\title{
ECONOMIC PROJECTION AND EVALUATION OF MINING VENTURE
}

\author{
Jozef Čech, Marian Šofranko
}

\section{Introduction}

Traditional methods of economic evaluation by techniques of investment and financial analysis with regards to the specifics of business, engineering and project economics are well known, e.g. (Gillespie, 2013; Newnan et al., 2013; Mian, 2011). Their use in mining evaluation is well adopted. The groundwork in the given field was done and provided in (Gentry \& O'Neil, 1984) with following (Runge, 1998). More sophisticated math approach is represented by application of option value paradigm added to classical investment analysis, taking into account managerial aspect of decision flexibility during the project's life. One of the first application to mining appeared within (Xiaoli \& Elbrond, 1996) and to take a more recent, e.g. within (Hall \& Nicholls, 2008) and (Saluga, 2011). In general, it justifies reason to add to the net present value (NPV) a premium (option value) which can increase project's value and thereby chances for feasibility of venture under study. Real options analysis can explore alternative approach, such as delaying development, project expansion in the future or leverage to the commodity prices. These methods require either use of decision trees (scenarios) approach or application of adequate math real option model, e.g. (Guthrie, 2009; Kodukula \& Papudesu, 2006) or (Slade, 2001).

However, we must keep in mind simplifications inherited within the respective formulas of many investment indicators (e.g. PBP, NPV, IRR, ROA and so on) as well as for the real options valuation (Jones, 2012; Lee et al., 2009; Hynek et al., 2015). Additionally, in such applications used data only hardly reflect the economic reality stemming from often complicated and conditioning natural, technical and economic circumstances. We could think of these indicators that they are of more theoretical nature and that it could be more preferred to get more concrete answers to more practical questions. For examples, what there will be Net Worth on balance sheet in the particular time periods, or how much cash there will be at the end of venture on a credit account, or even how much there will be debt indicated in financial statements and so on.

Taking into considerations complex reality within mining, there are many aspects of engineering that can play crucial role in evaluation of such venture. Typical examples are timely and spatially conditioned courses of activities and their performances due to irregular mineral deposit structures. Similarly it is with changing economic conditions during anticipated venture. There are changing values of exogenous and endogenous parameters such as ore reserves and their grades, interest and exchange rates, taxes, prices, different costs, inflation trends, not to mention changes in funding, structure of owners and lenders with consequences on capital costs. Due to the discontinuous and fuzzy character of such values, taking a long-term horizon under investigation, math formulas can become deficient. So, what can be done to be close to the engineer's point of view, in order to get better understanding and cooperation between engineers and economists?

The basic idea behind the computer aided economic projection (CAEP) is to enable the engineering view and approach to a venture under study from the start of evaluation process (Vořišek et al., 2015). Engineers can during the venture modeling manipulate with particular objects (blocks of reserves, construction sites, works, buildings, equipment, facilities, activities, operations, even loans) and their attributes (natural, technical, financial and control ones) in construction style. It enables to bring them together into a consistent dynamic 
model to be ready for a projection run, resulting standard financial statements in defined time periods. In principal, the ability to reflect states and flows of key item values over time into financial statements, gives incomparably greater possibilities for insight and investigation of a venture than the currently used methods. With the CAEP a venture designer can change not only the values of key decision variables, but also structural properties and relations with discontinuities in time and space of venture, better approximating the reality (Birkhofer, 2011). If the real option paradigm is considered, it is always possible to set different scenario during venture model projection, e.g. alternating scenario at certain time point or at a relevant event.

\section{Problem Formulation}

For a rigorous definition of the problem it can be effectively used the concept of theory of control, e.g. (Bequette, 2003; Smuts, 2011), and its apparatus. Let's have a dynamic system $S$ as a venture case with state vector $x(a, d, t)$ where $(a, d, t) \in A \times D \times T$ is an product element of activities $A$, domain $D$ and time $T$. There is known a beginning state of the system in $t=0$ and final state of the system in $t=k$. Task is to find such trajectory of states in phase space of the system $S$ defined over $A \times D \times T$ :

$$
\{\underset{A D}{ } x(a, d, t)\}_{t=0}^{k}
$$

to apply:

1. In natural terms projection:

$$
\begin{gathered}
W(x(a, d, t))=\underset{\text { TA D }}{\operatorname{UUU}} u(x(a, d, t)) \\
m(W(x(a, d, t))) \rightarrow \max
\end{gathered}
$$

where $x$ is a state vector of identified (by nature) and designed (by design and plan) values of attributes of the elements $(a, d, t) ; u$ - function, projecting the state vector $x$ into natural values of used resources and produced outputs; $W$ - functional, defined over the set of possible trajectories of system $S$, representing reports of proposals in natural terms; $m$ - evaluation operator, conveying optimality of the values of functional $W$, i.e. the reports of proposals, subject to

$$
\text { for each }\left(a_{p} t\right) \in A \times T: \bigcup_{D} p(x(a, d, t))=P L P_{t}
$$

where $p$ is a function, projecting vector $x$ into values of watched indicators of a production plan given for the system $S$ as $P L P_{t}$, for $t=1,2, \ldots, k ; a_{p}-$ production activity within activities $A$, generating planned products,

for each $x(a, d, t)$ :

$$
\begin{aligned}
& r_{t}\left(x\left(a, d, t_{i}\right), x\left(a, d, t_{i+1}\right)\right) \in P Z S T \\
& r_{d}\left(x\left(a, d_{i}, t\right), x\left(a, d_{i+1}, t\right)\right) \in P Z S D \\
& r_{a}\left(x\left(a_{i}, d, t\right), x\left(a_{i+1}, d, t\right)\right) \in P Z S A
\end{aligned}
$$

where $r_{t}, r_{d}, r_{a}-$ convey state changes, qualified for advance in time, domain and activities; PZST, PZSD, PZSA - represent set of values limiting admissible changes of states within the advance in time, domain and cooperating activities.

Requirements for a design and a plan of a venture case are formulated by these constraints. Particularly, keeping it with right progress in terms of time, domain and activities. All that to meet requirements for technologically rational advancement and state changes according to intensities possible in given time and space. Also to meet requirements for state changes admissible from viewpoint of technological cooperation and safety, as well as admissible from viewpoint of consecutiveness and required mutual distances of activities. Such a correct development of modeled venture is assumed to follow the basic pace and expansion of the core production activity defined already by the constraint (3).

2. In economic terms projection:

$$
\begin{gathered}
F S R_{t}(x(a, d, t))=\underset{A P}{U} v(u(x(a, d, t))) \\
n \underset{T}{n\left(\mathrm{FSR}_{t}(x(a, d, t))\right) \rightarrow \max }
\end{gathered}
$$

where $x$ is a state vector of identified and designed values of attributes of the elements $(a, d, t) ; u$ - function, projecting the state vector $x$ into natural values of used resources and produced outputs; $v$ - function, projecting function $u$ into monetary values of used resources and produced outputs, i.e. in monetary units; $F S R_{t}$ - functional, defined over set of possible trajectories of system $S$ as venture case, representing financial standard reports (income statement, balance sheet, cash 
flow statement and investors structure changes), arranged over time $t ; n$ - evaluation operator, conveying optimality of values of functional $F S R_{t}$ over time, e.g. by investment and financial indicators and analyses, or by a team expertise.

The formulated problems (2), (5) become unsolvable by methods of contemporary theory of control, i.e. by methods stemming from the mathematical disciplines of standard sets and operators as are differential calculus, calculus of variations and so on.

There was a need to come up with more prospective, experimental methods in the given field, stemming from computer oriented method of projection, which is represented here by the original technique of Computer Aided Economics Projection (CAEP system and applications, Eldtredi, Ltd.). The principle rests in creating of an engineering economic model of venture under study in form of its progress in time and space, i.e. as a dynamic prototype of venture case in computer with aim to optimize it. Such model building requires a set of instruments available to user to define as truthfully as possible any real venture and its economic situation and to get and to display its results in a convenient form (Guimaraes et al., 1992; Power \& Shardea, 2007; Walkenbach, 2010). As the evaluating operators, apart from predominately expert team appraisals, the different methods of assessment using multi-criteria approach are available, e.g. weighting and scoring, AHP, group decision making techniques and others (Ishizaka \& Nemery, 2013; Voronin, 2014).

\section{Computer Realization}

\subsection{Model Building}

The model building (Fig. 1) requires a set of instruments available to user to model given mining venture. For this purpose are defined such facilities, abstracts or elements, as follows:

- domains and their articles, modeling blocks of reserves or rock mass, and also construction sites with premises, to approximate deposit and surface layout, which can be purposely structured. Reserve domains comprise always some stock of articles impacting revenue, in given practical case the potential volume of components such as $\mathrm{Cu}, \mathrm{Ag}, \mathrm{Au}, \mathrm{Fe}$. Such reserves are subject to transformation by different processes carried over up to the final products to sell. Generally, domains with their articles represent mainly set of frames with some targets as a revenue potential to be processed and realized in economic sense. Other domains can serve to denote places for defined works and processes.

- works and their inflows and outflows, modeling different procurements and operations according to their specific purpose within exploration, development, opening, preparation, stoping, extraction, mineral processing, liquidation and reclamation, which are designed and planned in certain structure and sequence. Operation, including procurement, in general, can be an elementary activity

\section{Fig. 1: Scheme of mining venture model and its statements}

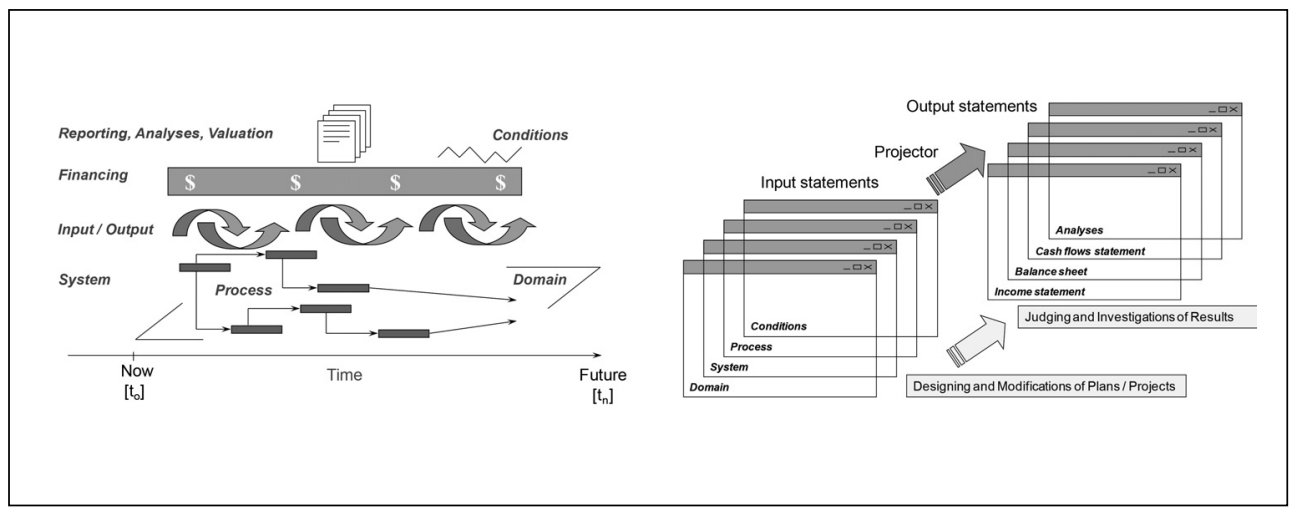


resulting into a visible work in deposit space, or transforming something into new forms or state, or it can represent accruing physical capital like building and equipment, or is just consumption operation without such effects in domain. During their development in natural units as processes, the works are consuming some resources as inflows and makes some waste products as outflows. E.g. during stopping or excavation it can include different material supply, energy, fuel and workforces on the input side, and production of water, scraps, exhaust fumes and others on the output side. Every work has defined specific consumption rate of resources and specific waste production rate for individual items of inflows and outflows. Such works can then be perceived as certain construction elements with flexible parametric setting. They can be differently dimensioned and deployed into defined domains with a concrete technical and economic purpose by venture designer intentions.

- processes and their programming, setting and modeling dynamics of defined works as running operations in space and time and as a growing tree structure to enable to define different conditional relationships among the progressing and cooperating operations. Every complex activity can be coded and modeled by such a tree of works. The tool enables to design and to plan technologically correct course of activities in given deposit space. An elementary process, as a branch of such tree, is programmed firstly by assignment of work to a domain and then setting its performance and conditions for material and time handling during its projected growth.

- economic items and their values, modeling effects in material and economic values as consequences of designed and planned processes in space and time, at given outside economic conditions. In such a way an economics of venture under study is always represented by values of exogenous items (changes of outside economic conditions) as are dispatching capacity, prices, taxes, interest and exchange rates, inflation, funding, as well as endogenous ones (changes of inside economic conditions) as are material flows of resources and products, and value flows of costs, benefits, revenues, taxes and others. The economic value flows are arranged into integrated income statements, balance sheets, cash flow statements and statement of changes in shareholders' equity, all that in defined time periods. It makes a base for computing a number of indicators usually required within investment and financial analyses for evaluation and decision support analysis. Setting some input items as random or fuzzy allows for sensitivity and risk analyses. Similarly, setting certain special conditions enables to carry out what-if analyses. Defining the most pessimistic, the most likely, or the most optimistic conditions for the venture under study, enables to carry out scenario analyses. Possibilities to other analytical studies are open.

\subsection{Model Programming}

Within the programming of processes which are modeled as a growing tree structure of works there must be firstly decision on their placing in deposit space as well as decision on their spatial development and pace on deposit. All these aspects are assignment of the model programming. The programming during a computer session can consist of two following phases. The first one is planning solely extraction as a core process within framework of mining venture, taking into account mining restrictions, demand for the final production and possible capacities of extraction. The second one is planning all the cooperating processes together, respecting already the approved plan of extraction. The core plan works out an optimal spatial advance and pace on given deposit with certain selection of reserves to be extracted. In such way it determines also overall expansion of the other conditional processes by linking them to the core ones, thus implying also a certain life expectation of whole venture. The model programming consists then in setting planned values of control parameters for particular works of the defined tree structure by a team expertise or by support of math subroutine results. Thereby is ensured a correct development of overall venture process on the base of foregoing approved production plan.

\subsection{Model Projection}

The projection of a variant of mining venture can be performed by computer immediately after 
the user's model programming is completed. The projection itself consists in displaying of growth of particular works as branches of the defined tree structure in space of deposit in defined time scale. The driven growth of the works as certain processes consequently invokes sequence of changes in states and flows of the economically and environmentally relevant resources and products, recording it into the defined economic items. Such a projection is possible to perceive as series of economically significant events within the proposed venture, which are displayed and reported by development of the defined works in their specific units and by computed course of natural and economic values of the defined economic items over time. Overall development of venture, in the individual work progresses and in the individual input and output flows, all that in natural and monetary units over defined time horizon, is thus recorded, displayed and available.

\subsection{Model Evaluation}

A complete projection as a model of proposed mining venture can then be evaluated by more realistic analysis and assessment regarding many engineering aspects. The economic items in natural form represent spent resources and generated products, including wastes, in defined units, whereas the economic items in monetary form are different calculated costs, revenues, taxes and other economic/financial items, all due to the development by works in time. The economic evaluation is then represented mainly by appraisal of, finally from the economic item values arranged, financial standard statements/reports (the FSR in math model above) in particular time periods and in a summary after end of modeled venture. On the base of balance sheet, income statement, cash flow statement and statement of changing shares of owners, investors or lenders, many investment and financial indicators and ratios can be defined, reflecting viability and efficiency of proposed venture under study (e.g. NPV, IRR, ROR, PI, B/C, NetWorth, ROE, EPS and others). The possibility of many analyses, as already mentioned above (financial, investment, sensitivity, risk, scenario and whatif), is enabled as well. Additionally, the financial diagnostics available in individual time periods allows for real option valuation and analysis of the proposed venture.

\subsection{Model Optimization}

To optimize a venture model in given case means experimenting with values of its parameters (the operator $m$ and $n$ in the math formulation of problem above) to search for the best results in the financial statements, indicators and appended analyses as standard outcomes (the functional $W$ and FSR in the math formulation of problem above). Such aim is possible to reach by improvement of engineering, investment, operation and financial decisions on the venture model under optimization, i.e. during making up a design and plan of venture under study. They have the crucial impact on the venture cash flow that is generally considered to be the "king" for any successful project or a business. In terms of the computer realization, the experiments are in essence proposed changes of values in attributes of the defined elements, i.e. in Domains, Works, Processes and Economic Items, when getting better results within the outcomes are expected.

\section{Example of Application}

A case study was done by the CAEP system, dealing with a feasibility assessment of mining venture on so-called Silver Vein ore deposit within the Maria mine near town of Roznava, eastern part of south Slovakia. The requirement for investigation of the viability rose on the base of new economic and technological conditions which give an optimistic prospective for such enterprise in the given locality. Despite of the prevailing negative sentiment, the lasting pessimism and the relative high riskiness in the mining industry particularly in the copper and steel metallurgy production, the mentioned vein is still an attractive unique polymetallic deposit in the region with a high unemployment rate. The Silver Vein has an estimated grade of silver averaging $400 \mathrm{~g} \mathrm{t.}^{-1}$ in the proved reserves up to the date, not mentioning the attractive grades of copper, iron and gold.

The venture (Fig. 2) has assumed to reopen currently conserved mine and successively to produce the flotation polymetallic concentrate processed into $\mathrm{Cu}$ and $\mathrm{Fe}$ concentrates as final products. It has assumed to employ the existing technological equipment still available and to some extent to modernize the mine. However, the main intention is concerned with improvement the mineral processing plant through an additional large investment of over 8M EUR. 


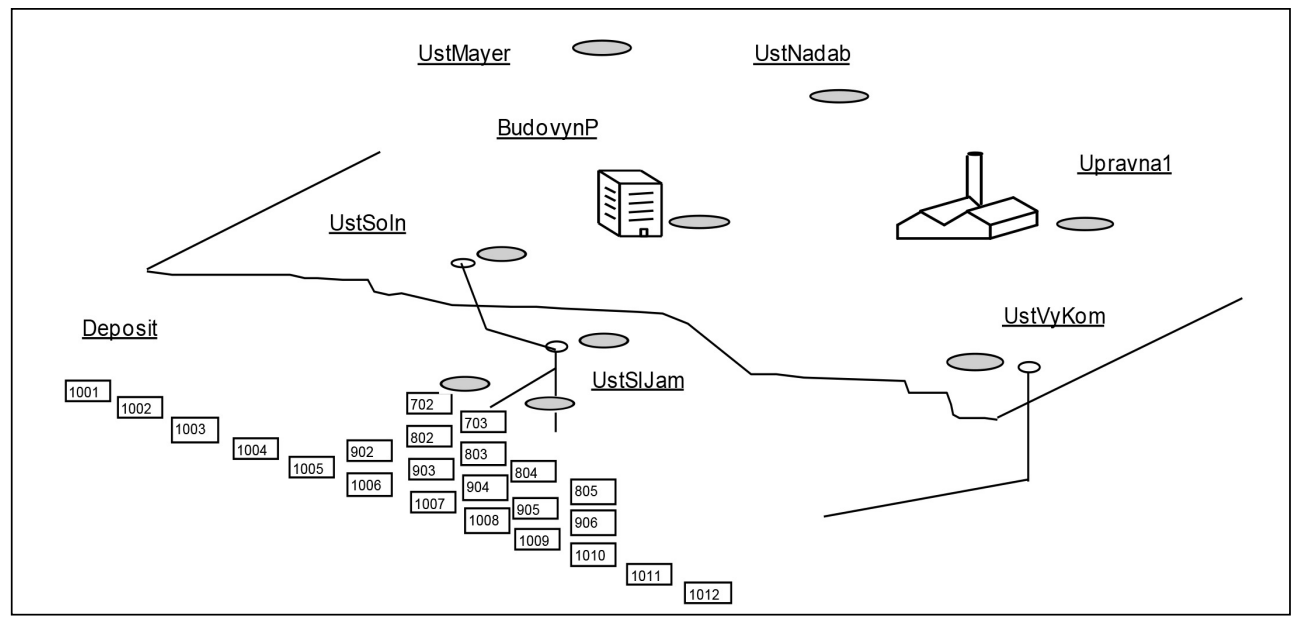

Source: own

The economic viability in question is supported by the results of the last geological exploration, by a new innovative hydrometallurgical treatment technology and also by potential long-term price trends of the metal components in ore $(\mathrm{Cu}, \mathrm{Ag}, \mathrm{Au})$ at the international metal exchange markets. A foreign buyer was ready to take up, from 110 kt yearly mined ore, whole year production of $\mathrm{Cu}$ concentrate according to the current LME prices of the key components, at the certain additional negotiable terms in the proposed contract. The most important ones that the study must take into consideration are represented by penalties for not meeting the grade limits for $\mathrm{Sb}$ and $\mathrm{Bi}$ in particular deliveries, FOB transport payments to the nearest port, including additional concentrate treatment costs, and to manage shipments in larger amounts before winter time to avoid frost. A domestic buyer was willing to buy all the year volume of side product, the $\mathrm{Fe}$ concentrate, according to a price agreement.

\subsection{Domains and Their Articles}

In mining venture they are represented by blocks of mineral reserves for extraction, with values of their key properties, and also by sites on mine surface to designate places with different premises and equipment. In the case of our vein deposit, as depicted in the Fig. 2, designer team firstly defined within the Domain statement a set of mining blocks: $B 0702-z 2$ up to $B 1012-z 2$. The numbers denote their position in the $z 2$ vein by mining horizon and by sequence in it. Secondly, there were defined significant sites on the surface: BudovyP (buildings) up to $V y K o m$ (ventilation raise). The individual blocks of mineable reserves are described by kilotons of ore and tones of key components: $\mathrm{Cu}, \mathrm{Ag}, \mathrm{Au}, \mathrm{Sb}, \mathrm{Bi}$ and $\mathrm{Fe}$, regarding already supposed ore dilution. The missing amounts of $\mathrm{Cu}$ and $\mathrm{Fe}$ concentrates are resulted implicitly from material flow modeling. All the blocks of reserves are approximately of the same bulk weights, for ore 3.894 t.m-3 and for waste 2.790 t.m-3. Important sites on the surface are defined as fictitious blocks, i.e. without any reserves. They serve as a designation for location of some works and operations, needed for the definition of their processes.

\subsection{Works and Their Inflows and Outflows}

The works within a mining venture are comprehended as a system of mine workings, equipment, operations and others, structured into particular subsystems according to their specific purpose. Such subsystems can be represented by mining, stages of haulages, different ensuring and support systems for mine, mineral processing, up to management and administration. Each of elementary works 
is described within the Works statement by its key attributes and parameters. First it is its unique name, encoding relevant information about, such as belonging to a subsystem, link to a defined article in the domains, technical and economical type and others. Next, its type of modeling, maximum performance rate in its defined natural units, and type of financing and so on are defined. Finally, there are given consumption rates for inflows of individual resources being used by given work, and analogically production rates for outflows of individual waste items. In total, there was 9 subsystems defined, from Mining (1st), Haulages (2nd, 3rd) through Mineral processing (6th) up to Management with administration (9th), with over 300 works.

\subsection{Processes and Their Programming}

Processes are defined as a complex of mutually conditional operations modeled as a growing tree structure of the defined works being localized on or passing through the defined domains. In the Processes statement is firstly defined timescale for such growth, i.e. development of modeled mining venture. In the next step, placement of the works to the domains are made in intentions of proposed mine design. The total quantity to be carried out in particular processes, percentage volume of produced rock waste and regulation of their production are given either straightly by the user or by using respective subroutines, e.g. in case of setting their outputs in a time in intentions of mine plan. The conditional starts and stops for individual processes in the next columns are referring either to a point on the timescale or to some preceding process to link them conditionally. This input statement is essentially a static representation of programmed dynamic process, ready to run in the next phase. As read in the Fig. 3, there was defined up to 329

\section{Fig. 3: Extract of the Processes statement}

\begin{tabular}{|c|c|c|c|c|c|c|c|c|c|c|c|c|c|c|c|}
\hline & & & & & & & & & 1 & 2 & 3 & 4 & 5 & 6 & 7 \\
\hline Act & Op & Domain & Work & Quant & Waste & RegOut & Start & Stop & 251 & 251 & 251 & 251 & 251 & 251 & 251 \\
\hline & 1 & B00702-Z2 & 1prekopV0 & 150.000 & 100 & & & & 150 & 0 & 0 & 0 & 0 & 0 & 0 \\
\hline & 2 & B0702-22 & \begin{tabular}{|l|} 
1 nudsypVo \\
\end{tabular} & 100.000 & 100 & & 1.0033 & & 100 & 0 & 0 & 0 & 0 & 0 & 0 \\
\hline & 3 & B0702-22 & 1slednaVo & 75.000 & 100 & & 2.0100 & & 75 & 0 & 0 & 0 & 0 & 0 & 0 \\
\hline & 4 & B0702-z2 & 1vyr1ald1S1 & 17.013 & & 0.11000 & 3.0100 & & 16.40375 & 0.609 & 0 & 0 & 0 & 0 & 0 \\
\hline & 5 & B00702-Z2 & 6uprkoncS1 & 9.527 & & 0.06160 & 4.0000 & & 9.1861 & 0.34104 & 0 & 0 & 0 & 0 & 0 \\
\hline & 6 & B0702-22 & $6 \mathrm{vyr} 2 \mathrm{kcuS1}$ & 1.021 & & 0.00660 & 4.0000 & & 0.984225 & 0.03654 & 0 & 0 & 0 & 0 & 0 \\
\hline & 7 & B0702-Z2 & $6 \mathrm{vyr} 3 \mathrm{kfeS} 1$ & 8.506 & & 0.05500 & 4.0000 & & 8.201875 & 0.3045 & 0 & 0 & 0 & 0 & 0 \\
\hline & 8 & $B 0702-22$ & 6 vyr4cus1 & 261.340 & & 1.68975 & 4.0000 & & 251.9846 & 9.355093 & 0 & 0 & 0 & 0 & 0 \\
\hline & 9 & B:0702-Z2 & 6 vyr5ags 1 & 6.390 & & 0.04131 & 4.0000 & & 6.16092 & 0.228728 & 0 & 0 & 0 & 0 & $\overline{0}$ \\
\hline & 10 & $\mid B 0702-\not 2$ & 6vyr6auS1 & 0.009 & & 0.00006 & 4.0000 & & 0.008935 & 0.000332 & 0 & 0 & 0 & 0 & 0 \\
\hline & 11 & B0702-Z2 & $6 \mathrm{vyr} 7 \mathrm{sbS1}$ & 301.126 & & 1.94700 & 4.0000 & & 290.3464 & 10.7793 & 0 & 0 & 0 & 0 & 0 \\
\hline & 12 & B0702-Z2 & 6vyr8bis1 & 5.869 & & 0.03795 & 4.0000 & & 5.659294 & 0.210105 & 0 & 0 & 0 & 0 & 0 \\
\hline & 13 & B0702-Z2 & $6 \mathrm{vyr} 9 \mathrm{feS} 1$ & 3.504 & & 0.02265 & 4.0000 & & 3.378188 & 0.125417 & 0 & 0 & 0 & 0 & 0 \\
\hline & 14 & B0703-z2 & 1vyr1ald1S1 & 16.248 & & 0.11000 & 4.0000 & & 16.24775 & 0 & 0 & 0 & 0 & 0 & 0 \\
\hline & 15 & $\mid B 0703-\not 2$ & 6uprkoncS1 & 9.099 & & 0.06160 & 14.0000 & & 9.09874 & 0 & 0 & 0 & 0 & 0 & 0 \\
\hline & 16 & B0703-22 & $6 \mathrm{vyr} 2 \mathrm{kcuS} 1$ & 0.975 & & 0.00660 & 14.0000 & & 0.974865 & 0 & 0 & 0 & 0 & 0 & $\overline{0}$ \\
\hline & 17 & B0703-22 & $6 \mathrm{vyr} 3 \mathrm{kfeS} 1$ & 8.124 & & 0.05500 & 14.0000 & & 8.123875 & 0 & 0 & 0 & 0 & 0 & 0 \\
\hline & 18 & B0703-Z2 & $6 v y r 4 c u s 1$ & 627.875 & & 4.25082 & 14.0000 & & 627.8748 & 0 & 0 & 0 & 0 & 0 & 0 \\
\hline & 19 & B0703-Z2 & 6 vyr5agS1 & 14.070 & & 0.09526 & 14.0000 & & 14.07006 & 0 & 0 & 0 & 0 & 0 & 0 \\
\hline & 20 & B0703-Z2 & 6vyr6aus1 & 0.009 & & 0.00006 & 14.0000 & & 0.00885 & 0 & 0 & 0 & 0 & 0 & 0 \\
\hline & 258 & Stoln & 3tazzarP1 & $\overline{9999.000}$ & & & 4.0000 & $\overline{233.0100}$ & 149.125 & 251 & 251 & 251 & 251 & 251 & 251 \\
\hline & 259 & SiJam & 7odvodnP1 & 9999.000 & & & & \begin{tabular}{|l|l|}
233.01000 \\
\end{tabular} & 251 & 251 & 251 & 251 & 251 & 251 & 251 \\
\hline & 260 & Stoln & 7osvetlP1 & 9999.000 & & & & 233.0100 & 251 & 251 & 251 & 251 & 251 & 251 & 251 \\
\hline & 261 & VyKom & 7vetranP1 & 9999.000 & & & & 233.0100 & 251 & 251 & 251 & 251 & 251 & 251 & 251 \\
\hline & 262 & Stoln & 4cazelDP0 & 9999.000 & & & & 4.0000 & 101.875 & 0 & 0 & 0 & 0 & 0 & 0 \\
\hline & 263 & Stoln & 4cazeIDP1 & 9999.000 & & & 4.0000 & 233.0100 & 149.125 & 251 & 251 & 251 & 251 & 251 & 251 \\
\hline & 264 & BudovynP & 8kornpMBP0 & 9999.000 & & & & 4.0000 & 101.875 & 0 & 0 & 0 & 0 & 0 & 0 \\
\hline & 265 & BudovynP & 8kornpMBP1 & 9999.000 & & & 4.0000 & 233.0100 & 149.125 & 251 & 251 & 251 & 251 & 251 & 251 \\
\hline & 266 & BudovynP & 8kotolnP1 & 9999.000 & & & & 233.0100 & 251 & 251 & 251 & 251 & 251 & 251 & 251 \\
\hline & 267 & BudovynP & 8trafMBP0 & 9999.000 & & & & 4.0000 & 101.875 & 0 & 0 & 0 & 0 & 0 & 0 \\
\hline & 268 & BudovynP & 8trafMBP1 & 9999.000 & & & 4.0000 & 233.0100 & 149.125 & 251 & 251 & 251 & 251 & 251 & 251 \\
\hline & 269 & BudovynP & 8vsttrafiP1 & 9999.000 & & & & 233.0100 & 251 & 251 & 251 & 251 & 251 & 251 & 251 \\
\hline & 270 & BudovynP & 8udrzMBP0 & 9999.000 & & & & 4.0000 & 101.875 & 0 & 0 & 0 & 0 & 0 & 0 \\
\hline & 271 & BudovynP & 8udraMBP1 & 9999.000 & & & 4.0000 & 233.0100 & 149.125 & 251 & 251 & 251 & 251 & 251 & 251 \\
\hline & 272 & BudovynP & 8laboraP1 & 9999.000 & & & & 233.0100 & 251 & 251 & 251 & 251 & 251 & 251 & 251 \\
\hline & 322 & & 9StrVybN & $\begin{array}{ll}1\end{array}$ & & & 1.0000 & & $\overline{~=1}$ & $=0$ & =0 & =0 & 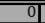 & $=0$ & 0 \\
\hline & 323 & & 9StrPCN1 & 1 & & & 4.0000 & & 1 & 0 & 0 & 0 & 0 & 0 & 0 \\
\hline & 324 & $\mathbf{u}$ & 6UverUI & 1 & & & 1.0000 & & 1 & 0 & 0 & 0 & 0 & 0 & 0 \\
\hline & 325 & $\mathbf{u}$ & 9UverUW & 1 & & & 1.0000 & & 1 & 0 & 0 & 0 & 0 & 0 & 0 \\
\hline & 326 & $\mathbf{u}$ & 9UverU00 & 1 & & & 1.0000 & & 1 & 0 & 0 & 0 & 0 & 0 & 0 \\
\hline & 327 & $\mathbf{u}$ & 9UverU01 & 1 & & & 4.0000 & & 1 & 0 & 0 & 0 & 0 & 0 & 0 \\
\hline & 328 & $\mathbf{u}$ & 9LverU02 & 1 & & & 0.0252 & & $\overline{0}$ & 1 & 0 & 0 & 0 & 0 & 0 \\
\hline & 329 & $\mathbf{u}$ & 9IverU04 & 1 & & & 0.0754 & & 0 & 0 & 0 & 1 & 0 & 0 & 0 \\
\hline
\end{tabular}


processes each with specific meaning and purpose.

\subsection{Economic Items and Their Values}

Many economic items are defined to determine external conditions of the venture under study and to record natural and monetary value flows and states, due to the processes and their linking to the different resources and products pools. External economic conditions are represented by values of exogenous variables with important impact on the venture under study. In this application, the following terms were taken into considerations: shipping schedule for $\mathrm{Cu}$ concentrate, because of seasonal conditions and capacity of railway facilities (from $8 \mathrm{kt}$ in second year, then $7,7,7,6,7,6,7,3.5,2 \mathrm{kt}$ in the next years respectively, up to $1.7 \mathrm{kt}$ in the last - the twelfth year); exchange rate for USD (0.766 EUR) regarding export to a foreign buyer; flat corporate tax rate $(19 \%)$; inflation ( $3 \%$ yearly); prices of concentrates according to relevant component contents (for the base case: 8,000 USD/t Cu, 33.5 USD/oz Ag, 1,700 USD/oz Au, with penalizing contents of $\mathrm{Sb}$ and Bi over $1.25 \%$ and $0.05 \%, 20$ USD $/ 1 \%$ and 150 USD/1\% respectively, and 8,962 EUR/kt for Fe concentrate); transport cost terms by FOB plus additional processing costs for $\mathrm{Cu}$ concentrate (795 USD/t); interest rates on credit $(0 \%)$ and debit $(7 \%)$. Some of the variables were defined in dynamic random fashion over timescale of 12 years to enable sensitivity and risk analysis. Regarding to long-term trends, the expected values are justified. Duties to the government and self-government (mainly charges for mined minerals, mined space and environmental burdens) amounted to 1,127.763 EUR'000 annually. Investments in form of private equity and obligations with dividend and interest payments over time were also possible to include. They would bring changes in shares of investors or owners as well as in capital costs during the venture. All these values of items represent input data of the Economic items statement.

On output side of the Economic items statement are then recorded values of items in natural and monetary units following from the evolution of modeled works as processes. They are the mentioned different produced articles, in the given case: ore, the concentrates and their components, different spent economic resources, produced rock waste and other wastes, accrued costs, received revenues, taxes and others, all by defined time periods, in the given case - years. In principle, it stems from modeled natural development, flows and states, and consequently from them derived economic value flows and states. The latter are finally arranged into integrated dynamic income statement, balance sheet and cash flow statement and so on, as a projection of the financial standard reports for evaluation of modeled venture under study.

\subsection{Projection of Processes}

As indicated within the Processes statement in shadow cells (Fig. 3), development of individual processes is projected over the timescale by their realized quantity in respective works' units defined in the Works statement. For instance, the process 1 , representing excavation of main crosscut by the work 1prekopV0, 150m long, is done all within the first year. The process 4 , representing a mining by the work $1 \mathrm{vyr} 1 \mathrm{ald} 1 \mathrm{~S} 1$, extracting total $17.013 \mathrm{kt}$, is realized about $16.404 \mathrm{kt}$ in the first year and left about 0.609 $\mathrm{kt}$ in the next year. Similarly, the process 258, haulage operation 3tazzarP1, is running for about 148 days to the end of first year (after leading time, starting with mining process 4) and then for full 251 working days each year up to the end of the mining venture. Its natural units are working days, to catch its periodical operational costs accruing on the time base. As for financial processes, e.g. the process 329 as the last one, represents repayment of the Ioan 9UverU04 with the defined start on 754th day, i.e. in the forth year, when the annuity installments start running up to the maturity date defined in the Works statement.

\subsection{Projection of Economic Items Natural value flows}

This statement provides projection of natural value courses of economic items over defined time periods, as are resources consumed by processes as well as produced commodities and wastes generated by processes in their natural units as are defined in the Works statement.

The natural value flows are displayed in a graph form on Fig. 4. Firstly, for defined resources and wastes, as are labor, material, energy, fuel, and so on, ending by salvage. Then, for defined articles in the domains as are ore, $\mathrm{Cu}$ concentrate, $\mathrm{Fe}$ concentrate and 


\section{Fig. 4: Layout of natural value flows within projection of economic items}

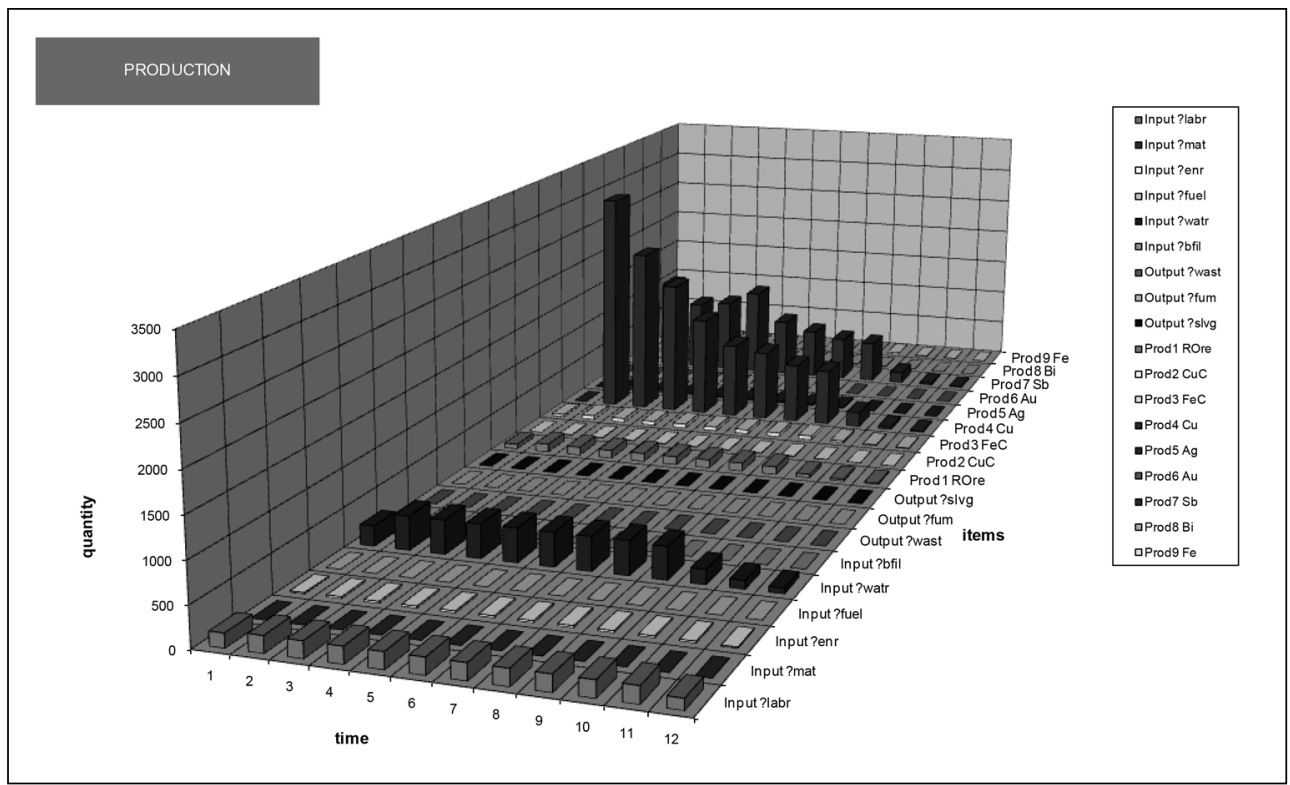

Source: own

respective components $\mathrm{Cu}, \mathrm{Ag}, \mathrm{Au}, \mathrm{Sb}, \mathrm{Bi}, \mathrm{Fe}$. A table form is always available either. In such graph usage, it is suitable then to select data to get just the required by interactive handling with 3D graph and its source data.

\section{Economic Value Flows}

This large statement provides projection of monetary values courses of economic items over defined time periods as are different costs and revenues, duties, profit and cash flow, but also financial ratios and some indicators for evaluation of the venture under study. For a comfortable assessment of the venture it is preferred to arrange such value flows and states of items into standard financial reports in table and graphical form. The most sought after are Balance sheet (reflecting states of property and capital available), Income statement (reflecting profit performance) and Cash flow statement (resulting free cash flow available), all that for particular defined time periods, with addition of statements about shares of investors and lenders, funding venture (if varying over time) and reports of performed analyses.
The Income statement and the Balance sheet are displayed in Fig. 5 and Fig. 6. The cash flow statement is omitted, but in principle it is always possible to derive from those two basic statements. As read there, the decisive items within the Income statement, earnings, and within the Balance sheet, free cash flow, both indicate a positive course of the modeled venture. Although, in the former it is in a downward trend due to worsening conditions on deposit with mining progressing deeper, and in the latter it is in mildly upward trend due to the cumulative effect of coming earnings. All that is resulting in the overall positive growth in the assets within the Balance sheet of the modeled venture. In such a way, the proposed venture under study indicates a successful business with ending level of assets consisting mainly in retained earnings in form of cash amounting to 195,127.934 EUR'000 and in remaining value of property 646.677 EUR'000.

\subsection{Indicators}

The key investment indicators are considered as generally accepted $P B P$ (pay back period), $N P V$ (net present value), IRR (internal rate 


\section{Fig. 5: Income statement within projection of economic items}
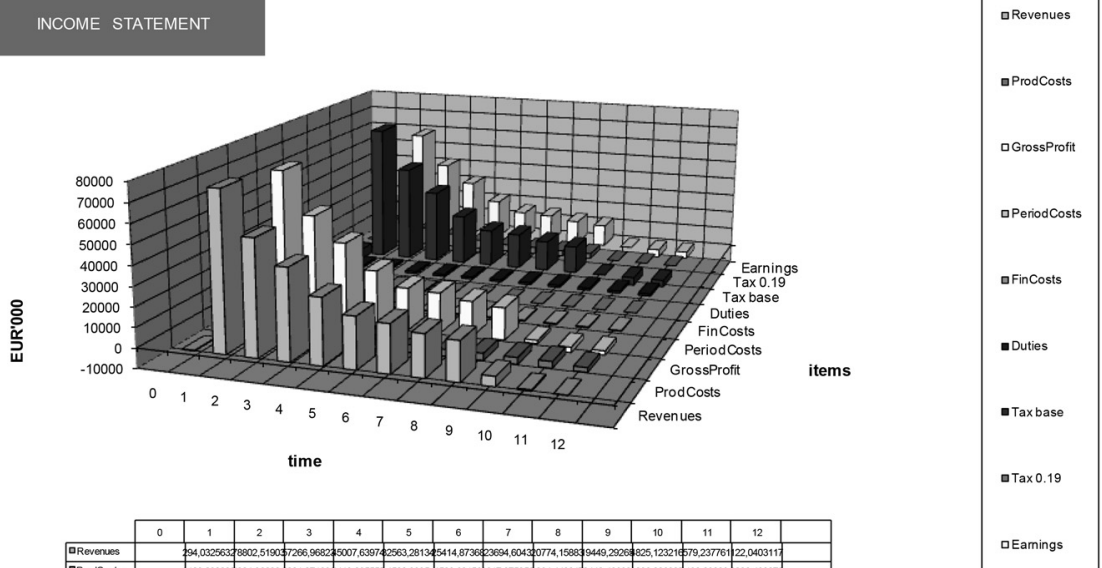

\begin{tabular}{|c|c|c|c|c|c|c|c|c|c|c|c|c|c|}
\hline & 0 & 1 & 2 & 3 & 4 & 5 & 6 & 7 & 8 & 9 & 10 & 11 & 12 \\
\hline QRevenues & & 94,032563 & 88802,51903 & 67266.96827 & 55007,6397 & 2566,23134 & 54414,8736 & 23694,6043 & 0074,15888 & 8949,29269 & $1825,12321 \% \bar{\phi}$ & 79,237761 & 22,040311 . \\
\hline DFrodCosts & & 1123,293098 & 3304,966224 & 4281,271298 & 2413,03585 & 4502,3935 & 1508,631156 & 617,37535 & 284,44331 & 3442,40689 & 236,026929219 & 198,090084 & 200,43007 \\
\hline$D_{\text {GrossProfit }}$ & & 8299,20053 & 304497,55225 & 2995.6909 & 40594,0041 & 80000.83739 & $0 s 06,2421$ & 0007,2289 & 7489.7155 & 26006,86579 & 559,096299420 & $618 ., 85232$ & 0078,44276 \\
\hline DPentioc osts & & 35,033484 & 665.95707 & 8762756199 & 976,551231 & 887,4437839 & 99,004553 & 100,359492 & 21,106917 & 433,7401249 & 446,752328960 & 80.1540964 & $006,9953 c 59$ \\
\hline DFinCosis & & 204,28721 & 239,167779 & 660,900346 & 006,213935 & 666,3018339 & 0 & 0 & 0 & 0 & 0 & 0 & 0 \\
\hline Dutles & & 127,76339 & 4127,76339 & 1127,763398 & 1127,76393 & 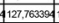 & 1127,76339 & 4127,763394 & 127,763394 & 21127,763394 & 1127,76339912 & $127,76339 \mathrm{~g}$ & 127,76330 \\
\hline ITax base & & 8497,34462 & 22164.92592 & 00820.6673 & 88584,0761 & 16279.373828 & 9379,4737 & 18540,10600 & 15940,8452 & 24445,36229 & 4,5005686442 & 206,77064 & 2513,19152 \\
\hline \begin{tabular}{|l|l|} 
Tax 0.19 \\
\end{tabular} & & 0 & 13711,33599 & 6655.926002 & 330,97446 & 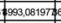 & 662,10001 & 0522,62015 & 022,700500 & 4744,622622 & 70030007 & 0 & 0 \\
\hline DEannings & & 5497,34462 & 2558453,591 & 11164.74058 & 1253,1018 & 321286,29689 & 56697,3737 & 45017,4856 & 2012,08464 & 17700,7506 & 1,8102607 & $200, \pi$ & 13,1915 \\
\hline
\end{tabular}

\section{Balance sheet within projection of economic items}

\section{BALANCE SHEET}

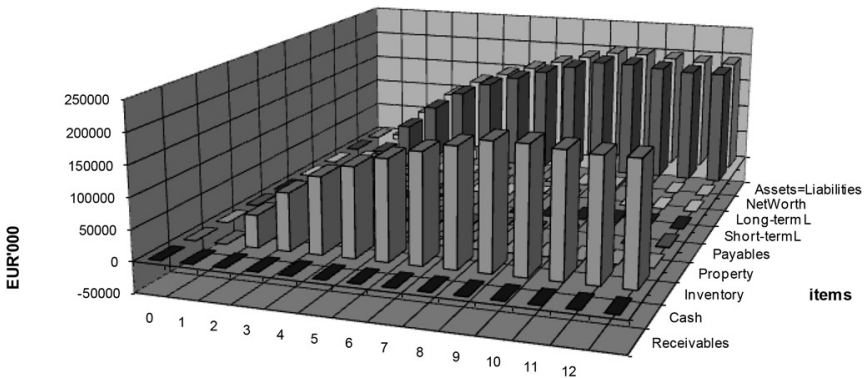

time

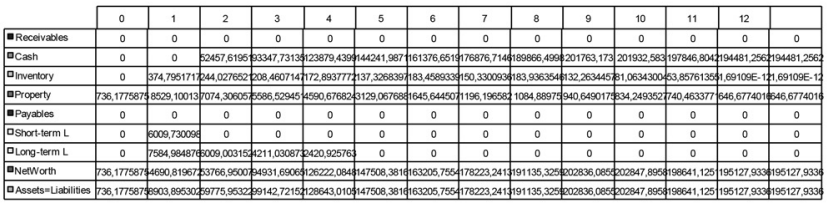

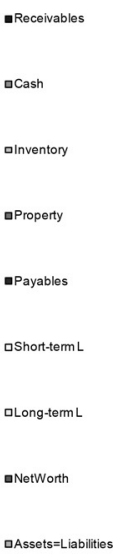

口Assets=Liabilities 
of return), ROR (rate of return), B/C (rate of benefit and cost), EPS (earnings per share) and Net Worth in balance sheet. The definition of others is open, because many items and values potentially required are available. They can be displayed in table or graph form with the final values in given case: $B / C$ of $4.64, N P V$ of $194,481.256$ EUR'000, IRR of $783.83 \%$, ROR of $539.69 \%, P B P$ of 251 days and EPS with a maximum of 58,453.590 EUR'000 in the second year and finally as Net Worth per share with 195,127.934 EUR'000 available, when just one investor is considered. All the indicators show a positive outlook at the venture under study at given conditions.

\subsection{Analyses}

There are many types of analyses available, thanks to the rich base of data and results.
The financial analysis in the given research consist in assessment of financial ratios and investigating different means of financing, i.e. by equity, loans or obligations with different capital costs accruing. The investment analysis is dealing with overall viability of venture and different alternatives of capital allocation into assets. The sensitivity and the risk analysis focus on investigating impacts of random values of the key drivers, such as grades in deposit, prices, costs, inflation, on values of the key results, mostly NPV or Net Worth, and in case of risk analysis, displaying them as random variables with their frequency distribution. Analyses, such as scenario and what-if, generally provide a view of venture under study in pessimistic, most likely expected and optimistic conditions, and also in special cases being set in the modeled venture, that

\section{Fig. 7: Results of financial analysis of venture under study}

\begin{tabular}{|c|l|l|r|r|r|}
\hline Investment & EQT & DBT & NetWStart & NetWFinish & Ratio \\
\hline $\mathbf{8 2 9 8 . 4 8 0}$ & & loan8298.480 & $\mathbf{7 3 6 . 1 7 8}$ & $\mathbf{1 9 5 1 2 7 . 9 3 4}$ & $\mathbf{2 6 5 . 0 6}$ \\
\hline $\mathbf{8 2 9 8 . 4 8 0}$ & $\mathbf{8 2 9 8 . 4 8 0}$ & & $\mathbf{7 3 6 . 1 7 8}$ & $\mathbf{2 0 6 0 5 3 . 0 7 5}$ & $\mathbf{2 7 9 . 9 0}$ \\
\hline
\end{tabular}

\section{Fig. 8: Results of risk analysis of venture under study}

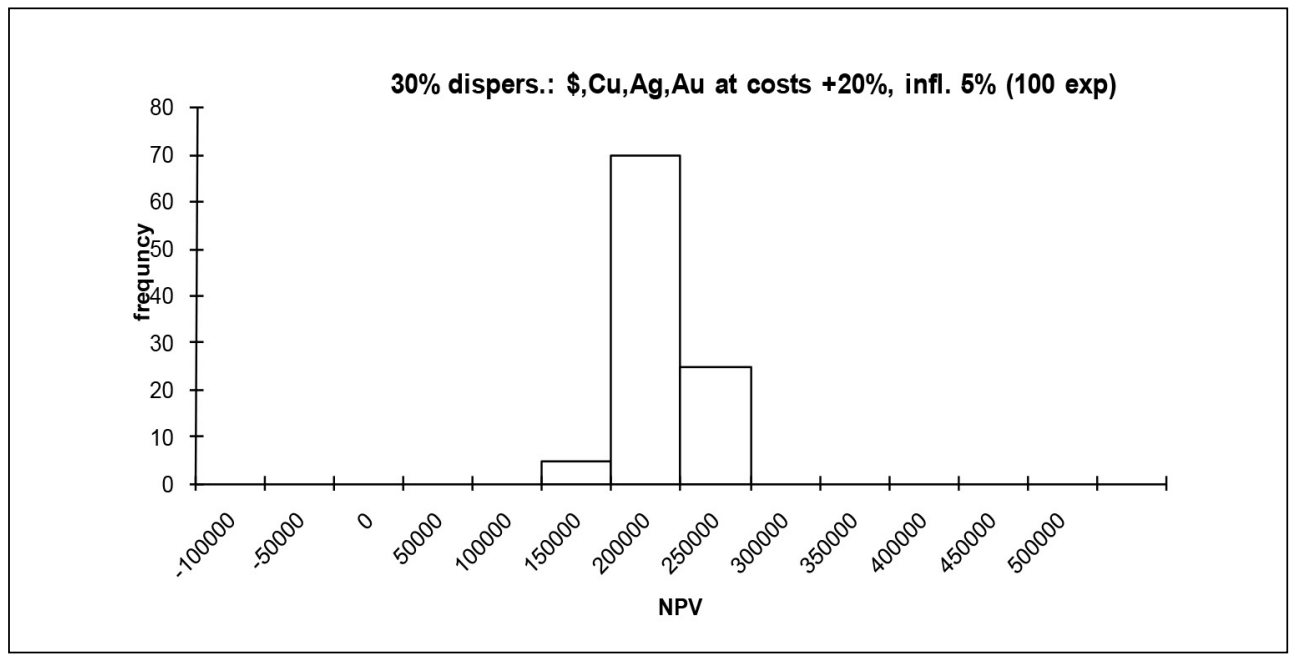




\begin{tabular}{|c|c|c|c|c|c|c|}
\hline Experiment & \multicolumn{3}{|c|}{1} & \multicolumn{2}{|c|}{2} & \\
\hline \multirow{2}{*}{$\begin{array}{l}\text { Variable } \\
\text { value }\end{array}$} & Recovcu,Ag,Au & RecovSb, Bi & InvLoan & $\$, \mathrm{Cu}, \mathrm{Ag}, \mathrm{Au}$ & $\operatorname{Tax}$ & \\
\hline & $89 \%+5 \%$ & $100 \%-20 \%$ & +3319.391 & 1EUR, $+20 \%$ & \multicolumn{2}{|l|}{$30 \%$} \\
\hline \multicolumn{7}{|l|}{ Impact } \\
\hline \multirow{2}{*}{$\begin{array}{l}\text { Variable } \\
\text { value }\end{array}$} & NetWorth & ROR\% & $B / C$ & NetWorth & ROR & $\mathrm{B} / \mathrm{C}$ \\
\hline & $>191296.664$ & $>425.47$ & $>4.34$ & $<296826.791$ & $<822.20$ & $<7.42$ \\
\hline
\end{tabular}

are interesting from viewpoint of researcher or financial analyst.

The financial analysis on Fig. 7 has investigated whether to settle the required investment of 8,298.480 EUR'000 for a new mineral processing technology by loans $(D B T)$ with tax deductible interest or by equity (EQT) without dividend payments, as mutually exclusive alternatives. Based on the final $\mathrm{Net}$ Worth values (NetWFinish) with better summing up the beginning Net Worth values (NetWStart) by some percents (Ratio), the use of equity financing without dividend payoffs seems to be more preferable at given conditions.

The risk analysis on Fig. 8 has considered random behavior of the USD exchange rate and prices of $\mathrm{Cu}, \mathrm{Ag}, \mathrm{Au}$ with their means given by the base, initial, case (mentioned in chapter 4.4) and with their dispersion of $30 \%$, along with a rise of costs by $20 \%$ and inflation trend of $5 \%$, when 100 experiments were carried out. Such setting of the values corresponds with possible averse external economic conditions relevant for risk study. The frequency distribution of the NPV values shows a minimal risk undertaken, since all the range of possible NPV values at given conditions is falling in positive part of $x$ axis.

For final example on Fig. 9, impacts on the key indicators of venture under study by setting special conditions are investigated in the following two what-if analyses. In the first, the recoveries for $\mathrm{Cu}, \mathrm{Ag}, \mathrm{Au}$ have increased by $5 \%$, and for $\mathrm{Sb}$ and $\mathrm{Bi}$ (the penalized) decreased by $20 \%$, all that due to a possibility for mineral processing to be more efficient by additional investment increase in the loan by 3,319.391 EUR'000. The impacts show a decrease in the values of key indicators, so the proposed investment does not bring expected positive effect. In the second, theoretical one, the USD exchange rate is set on 1 EUR (stronger USD is an advantage for exporter) and simultaneously the prices of $\mathrm{Cu}$, $\mathrm{Ag}, \mathrm{Au}$ have moved up by $20 \%$, all that at higher income tax on the level of $30 \%$. The final effect on the key indicators is a positive increase compared to the base case values.

\section{Results and Discussion}

After many projections with consideration of all the relevant aspects and scenarios, the results indicated that the given mining project with a life expectation of 12 years, is economically viable and with relatively low risk. A discussion recommended searching for even more profitable solutions and further reducing investment risk that would rely on selective mining at a smaller expansion on the deposit. It would focus on the first two mining horizons with relative higher grades of the crucial components $\mathrm{Cu}, \mathrm{Ag}$, and $\mathrm{Au}$.

The what-if analysis was to investigate the additional investments into an innovative flotation technology that would increase recovery of the useful components $(\mathrm{Cu}, \mathrm{Ag}, \mathrm{Au})$ and reduce the penalized ones $(\mathrm{Sb}, \mathrm{Bi})$. The aim was to increase revenues and minimise the losses due to not meeting the contractual quality limits. Such investment, however, did not bring expected positive effect in the results of key indicators such as Net Worth, ROR and $B / C$ rate. A risk analysis investigated the impact of the USD exchange rate, as a relevant factor in export business, including inflation trend and often unpredictable volatile behaviour of the metals prices in the world markets. The results indicated minimum risk undertaken at given conditions. Financial analysis of the key investment into mineral processing, funding by either equity or loan, made more favourable the equity option, but without consideration of dividend paid out during the venture's life and thus with a cumulative effect on the final value of Net Worth in the balance sheet. 
Investigating a tolerable losing venture can also be discussed. Cases of socially oriented mining, by taking poorer parts of the deposit as well and in such a way extending venture life with a subvention is possible to consider. A follow up research enables to quantify required subvention to support and make such a decision more objective. The intention is to maintain socially and economically justified production with regard to high unemployment rate and low economic growth in the given region.

\section{Conclusion}

The paper provided a view of new technique for economic projection and evaluation of mining venture. An application of such computer aided technique to an existing underground mine and abandoned mineral processing plant on the surface in the region of South Eastern Slovakia is briefly presented. The task was to assess viability of a proposed venture on a selected part of deposit called Silver Vein. The study was to provide overall evaluation of the venture, regarding many engineering aspects with eventually investment and financial analysis, risk and what-if analysis in defined cases. The results show viability and optimistic outlook for this venture, certainly, at given conditions. Additionally, the discussion has encouraged for future research. The intention is to try to search for a balanced, although less profitable, but more socially oriented subvention-aided mining venture with mine expansion beyond limits of the selected parts of deposit and thereby to prolong the life of mine and to back employment in given region.

The application of system had made an excellent verification of the presented technique in practice. Future applications being considered is to use the system at planning of highways and motorways within intensive reconstruction of transport infrastructure, being pursued at the present time in Slovakia.

\section{References}

Bequette, B. W. (2003). Process Control: Modeling, Design and Simulation. Prentice Hall Professional.

Birkhofer, H. (Ed.). (2011). The Future of Design Methodology. London: Springer. https://dx.doi.org/10.1007/978-0-85729-615-3.

CAEP (Computer Aided Economics Projection) system. Eldtredi, Ltd. The Slovak Repubic.
Gentry, D. W., \& O'Neil, T. J. (1984). Mine Investment Analysis. New York: SME.

Gillespie, A. (2013). Business Economics. Oxford: Oxford University Press.

Guimaraes, T., Igbaria, M., Lu, M. (1992). The Determinants of DSS Success: An Integrated Model. Decision Sciences, 23(2), 409-430. https://dx.doi.org/10.1111/j.1540-5915.1992. tb00397.x.

Guthrie, G. (2009). Real Options in Theory and Practice. Oxford: Oxford University Press.

Hall, J. L., \& Nicholls, S. (2007). Valuation of Mining Projects Using Option Pricing Techniques. Jassa, (4), 22-29.

Hynek, J., Janeček, V., \& Lefley, F. (2015). An Exploratory study of a comparison between the UK and Czech Republic of the financial models used in the appraisal of ICT and non-ICT capital projects. E\&M Ekonomie a Management, 18(2), 89-102. https://dx.doi. org/10.15240/tul/001/2015-2-007.

Ishizaka, A., \& Nemery, P. (2013). Multicriteria Decision Analysis: Methods and Software. John Wiley \& Sons. https://dx.doi. org/10.1002/9781118644898.

Jones, C. P. (2012). Investments: Analysis and Management. John Wiley \& Sons.

Kodukula, P., \& Papudesu, Ch. (2006). Project Valuation Using Real Options: A Practitioner's Guide. J. Ross Publishing.

Lee, A. C., Lee, J. C., Cheng F., \& Lee, Ch. F. (2009). Financial Analysis, Planning And Forecasting: Theory and Application. World Scientific.

Mian, M. A. (2011). Project Economics and Decision Analysis. PennWell Books.

Newnan, D. G., Lavelle, J. P., Eschenbach, T. G. (2013). Engineering Economic Analysis. Oxford: Oxford University Press.

Power, D. J., \& Shardea, R. (2007). Modeldriven decision support systems: Concepts and research directions. Decision Support Systems, 43(3), 1044-1061. https://dx.doi.org/10.1016/j. dss.2005.05.030.

Runge, I. (1998). Mining Economics and Strategy. Littleton, CO: Society for Mining, Metallurgy, and Exploration.

Slade, M. E. (2001). Valuing Managerial Flexibility: An Application of Real-Option Theory to Mining Investments. Journal of Environmental Economics and Management, 41(2), 193-233. https://dx.doi.org/10.1006/jeem.2000.1139.

Smuts, J. F. (2011). Process Control for Practitioners. League City, TX: OptiControls Inc. 
Saluga, P. (2011). Valuation of mineral project with simultaneous options. Gospodarka Surowcami Mineralnymi - Mineral Resources Management, 27(1), 101-113.

Voronin, A. (2014). Multicriteria DecisionMaking: Systemic Approach. LAP LAMBERT Academic Publishing.

Voříšek, J., Pour, J., \& Buchalcevová, A. (2015). Management of business informatics model - principles and practices. E\&M Ekonomie a Management, 18(3), 160-173. https://dx.doi.org/10.15240/tul/001/2015-3-014.

Walkenbach, J., Tyson, H., Groh, M. R., Wempen, F., \& Bucki, L. A. (2010). Office 2010 Bible. John Wiley \& Sons.

Xiaoli, T., \& Elbrond, J. (1996). An option approach to mining investment decisions. In R. V. Ramani (Ed.), 26th Proceedings of the Application of Computers and Operations
Research in the Mineral Industry. Littleton, Colo.: Society for Mining, Metallurgy, and Exploration.

doc. Ing. Jozef Čech, CSc. Technical University of Košice Faculty of Mining, Ecology, Process Control and Geotechnology Department of Montaneous Sciences Slovakia jozef.cech@tuke.sk

doc. Ing. Marian Šofranko, PhD. Technical University of Košice Faculty of Mining, Ecology, Process Control and Geotechnology

Department of Montaneous Sciences Slovakia Marian.Sofranko@tuke.sk 


\section{Abstract}

\section{ECONOMIC PROJECTION AND EVALUATION OF MINING VENTURE}

\section{Jozef Čech, Marian Šofranko}

The paper is dealing with a new approach and technique to evaluate entrepreneur ventures using computer aided economic projection system. The term "economic projection" represents ability to display given venture from engineer's point of view (in constructive, object and process-oriented way) into financial reports and indicators over time. Eventually it enables the user to carry out financial, investment, sensitivity, risk, scenario and what-if analyses according to requirements. It opens possibilities for changes in design or plan in order to optimize given venture in terms of economic results. The introduction contains some critical views of contemporary state in given field, i.e. in evaluation and feasibility assessment of such capital intensive and time demanding ventures. In the next, it is dealing with mathematical formulation of the problem underlying new method and its computer realization. Finally, it presents practical application of the technique to an existing underground mine and mineral processing plant. The task was to make assessment of viability of a proposed mining venture on a selected part of deposit called Silver Vein. The study was to provide overall evaluation of the proposed venture, regarding many engineering aspects with eventually investment and financial analysis, risk and what-if analysis in defined cases, which were presented. The results show viability and optimistic outlook for this mining venture, certainly, at given declared conditions. Additionally, the study has encouraged for future research. The intention is to try to search for a balanced, although less profitable, but more socially oriented subvention-aided mining venture with mine expansion beyond limits of the selected parts of deposit and thereby to prolong the life of mine and to back employment in given region. Future applications being considered is to use the system at planning of highways and motorways within reconstruction of transport infrastructure, being pursued at the present time in Slovakia.

Key Words: Mining venture, theory of control, computer aided, economic projection, investment analysis, financial analysis, sensitive analysis, risk analysis, scenario analysis, what-if analysis.

JEL Classification: G34, M12.

DOI: 10.15240/tul/001/2018-2-003 